\title{
Selective Sentence Production Deficit in an Agrammatic Yoruba-English Bilingual Patient with Minor Stroke: A Case Study
}

\author{
Gerald C. Imaezue ${ }^{1 *}$, Ibraheem A. Salako², Akinyemi T. Akinmurele ${ }^{3}$ \\ ${ }^{1}$ Department of Special Education, University of Ibadan, Ibadan, Nigeria \\ ${ }^{2}$ Institute of Child Health, College of Medicine, University of Ibadan, Ibadan, Nigeria \\ ${ }^{3}$ Department of English, University of Ibadan, Ibadan, Nigeria \\ Email: *geraldimaezue@gmail.com
}

How to cite this paper: Imaezue, G.C., Salako, I.A. and Akinmurele, A.T. (2017) Selective Sentence Production Deficit in an Agrammatic Yoruba-English Bilingual Patient with Minor Stroke: A Case Study. Journal of Behavioral and Brain Science, 7 , 416-424.

https://doi.org/10.4236/jbbs.2017.79030

Received: July 1, 2017

Accepted: September 19, 2017

Published: September 22, 2017

Copyright () 2017 by authors and Scientific Research Publishing Inc. This work is licensed under the Creative Commons Attribution International License (CC BY 4.0).

http://creativecommons.org/licenses/by/4.0/

\begin{abstract}
Speech helps us to communicate with our loved ones and significant others through construction of grammatically coherent sentences that are comprehensible to our communication partners. As such, impairment of this ability as a result of stroke can be debilitating and disabling to the patients as well as significant others. Agrammatism is deficit in the use and processing of grammatically coherent syntactic structures following damage to the Broca's complex or region. Most studies have traditionally emphasized monolingual patients, with bilingualism now receiving increased attention. However, few studies have specifically investigated the effect of minor stroke on agrammatic bilingual individuals. This study examined an agrammatic YorubaEnglish bilingual patient with minor stroke with a view to describing their sentence production (deficit). The findings strongly support the existence of distinct language-specific lexical-subsystem centres in the Broca's complex for native and acquired languages (Yoruba-English) whereas both languages are likely connected to a single semantic system in the anterior temporal lobe and its surrounding regions. Furthermore, acquired language is more susceptible to brain damage than native language. This might imply that severity of deficit in speech production in both native and acquired language of bilingual aphasics may be determined by the size of lesion in the Broca's complex or region.
\end{abstract}

\section{Keywords}

Agrammatism, Sentence Production, Stroke, Bilingual, English, Yoruba 


\section{Introduction}

Our ability to construct grammatically coherent sentences that are comprehensible to our communication partners helps us to communicate with our loved ones and significant others. As such, impairment of this ability as a result of stroke can be debilitating and disabling to the patients and significant others. Agrammatism is deficit in the use and processing of grammatically coherent syntactic structures following damage to the Broca's complex or region. Traditionally, it is suggested that syntactic ability is completely lost in agrammatic individuals and they rely on ungrammatical strategies to put words together to make a sentence [1]. However, Ardila [2] [3] suggests that agrammatic aphasics can produce only isolated meaningful words and words with pure grammatical functions (such as articles and prepositions) tend to be omitted in the speech of persons with agrammatic aphasia. The same author further suggests that affixes may be substituted one for another but more likely they are simply not produced and these patients tend to use only very short sentences containing mostly nouns. Kemmerer [4] suggests that agrammatic aphasics have impaired production of syntactically complex sentences characterized with markedly disrupted close-end elements, and worse retrieval of verbs than nouns. In severe cases, utterances can be as short as a single word [5].

Most studies have traditionally emphasized sentence deficit in speeches of monolingual patients. However, in recent times, agrammatism is now receiving increased attention among bilingual groups; research has recently revolved around the organization of language in the brain of bilingual aphasic individuals. Unfortunately, the question of the neural underpinning of multiple languages in bilinguals remains unresolved. Some studies report a single neural representation for multiple languages [6] [7]. This is called the "linguistic domain" approach. On the other hand, some other studies report that bilingual individuals could have distinct brain areas [8] [9] [10]. This has been termed the "languagemembership principle". According to this approach, native language (L1) and acquired language (L2) representations would to an extent be sustained by different brain areas, because they show different language membership values [11]. Consistent with the language membership principle, cases of selective aphasia and other findings obtained by neuroimaging techniques demonstrate dissociation between multiple language representations in the cognitive system of the brain [12]. Some factors influence cerebral organisation in bilingual individuals: the age/time of acquisition of the native and the acquired languages (early or late bilingual), manner of acquisition/learning of these languages, the degree of proficiency in these languages and linguistic environment.

Research on how sentence production of two languages is disrupted as a result of minor stroke in bi-lingual patients may contribute to an understanding of how language is represented in the human brain. The primary goal of the present study is to determine whether one or both languages (sentence production) 
of an agrammatic Yoruba-English bilingual individual are disrupted following minor stroke. The Yoruba language is one of the major languages in Nigeria with a syntactic structure (SVO) similar to the English language. However, the key distinctive feature of the Yoruba language (different from English) is its use of tone, which facilitates language production and comprehension. Analysis of deficits in sentence production has up to now been restricted largely to English and other western European languages. This descriptive study provides an opportunity to observe how this deficit is manifested in two languages whose linguistic structures do not differ substantially. In addition, it enables us to gain better understanding of the nature of selective impairment of syntactic structures in bilingual individuals.

\section{Methodology}

This case report utilized a qualitative descriptive research design. The participant, now called AA, of this study was an outpatient who was referred to a speech language pathologist for speech assessment and therapy. AA was a 50-year old male English-taught $\mathrm{PhD}$ student and teacher with pre-morbid high language proficiency in Yoruba (native) and English (acquired) before the sudden onset of minor stroke (two months' time of onset), based on his referral report and case history. Based on his case history, AA acquired and communicated in English for about 45 years. In addition, AA had no incidence of hemiparesis or hemispatial neglect and was right-handed. AA was an outpatient who was referred to a speech and language pathologist. Through the assistance of his spouse a signed written consent was obtained for this study.

AA was then screened for agrammatism using a self-designed aphasia screening test that employed the use of 20 production, 20 comprehension and 20 repetition tasks in English that progressed in complexity. AA performed poorly in production and repetition tasks but performed relatively better in the comprehension tasks. The participant's agrammatic speech was moderate in nature. The "Cookie Theft picture" by Goodglass \& Kaplan [13] was used to elicit spontaneous speech from the participant which was analyzed thereafter. The screening and assessment was done at AA's home and not in a clinical setting as requested by AA.

The structural analysis with discussion is done within the framework of X-bar module of Chomsky's Government and Binding theory.

\section{Data Analysis}

The analysis focused primarily on syntactic disruptions (SVO analysis) and word retrieval deficits. It should be noted that structures that are relatively coherent enough are selected for analysis here.

Text A: Yoruba (Participant's L1)

P: Ehh ehh mama >> öñ fo bobó fo abó^^^ níbíi>> ó gbá omi (omí) dànù >> níbí >> níbí ok níbí then ehh àbúrò >> eh>> àbúrò ó fé subú>>> ehh ó fé subú 
níbí ehh stool > t'ówà ñbí t'orí pé ó fé jade ${ }^{\wedge \wedge \wedge}$ tori p'ó fa ekeji e

\begin{tabular}{|c|c|c|}
\hline $\begin{array}{l}\text { IP,Spec,NPMama ö } \\
\text { (Mother) }\end{array}$ & $\begin{array}{l}V P \text { Inff. }^{\tilde{n}} \\
\text { (ASP.PROG) }\end{array}$ & $\begin{array}{l}\text { fọ (bobó fo) } \\
\text { (wash) }\end{array}$ \\
\hline
\end{tabular}

Mother is washing plate.

2) ${ }_{I P, S p e c, N P} \mathrm{O} \quad{ }_{V}$ gbá $\quad{ }_{N P} \mathrm{Omi}(\mathrm{omí}) \quad{ }_{P T}$ dànù $\quad{ }_{A d v}$ níbí

(3Sg) (sweep) (water) (particle; away) (here)

S/he sweeps away water (from) here.

3) ${ }_{I P, S P e c, N P}$ Àbúrò ó $\quad V P$, Inff fé $\quad$ subú.

(Younger sibling) (MOD) (fall)

The younger sibling wants to fall.

4) ${ }_{I P, S p e c, N P} \mathrm{O} \quad{ }_{V P}$, Inf fé ${ }_{\nu}$ subú ${ }_{A d r}$ níbí ${ }_{C O N J}$ tori $\mathrm{p}^{\prime}{ }_{I P, S p e c, N P} \mathrm{o}_{V P} \mathrm{fa}_{N P}$ ekeji è

(3Sg) (MOD) (fall) (here) (because) (3Sg) (pull) (second) (POSS)

He wants to fall here because he pulls his second.

Sentences 1 and 2 above have structures sequence of Spec, IP-VP-NP-AdvP (which gives SVOA). Structure 3 has Spec, IP-VP-NP (that is, SVO) where the object NP is an embedded clause; the participant correctly produced the embedded clause. Similar pattern is seen in structure 4 where the participant also produced the embedded clause correctly. In addition, sentence 4 is a complex sentence. Apart from the embedded infinitival clause, the structure contains a subordinate clause conjoined with the main clause. The structure of the subordinate clause is SVO (marked by Spec, IP-VP-NP). In all the structures, there is no instance of word order impairment neither is there any impairment of the constituent elements. For instance, the VP in 1 has auxiliary which expresses the (PROG) inflection of the verb; the participant correctly produced this. Again, sentence 2 contains a complex VP, being a phrasal verb (having the structure V + adverbial "away"); the production was intact.

Text B: English (Participant's L2)

$\mathrm{R}:$ (...language); Tell me what you understand in this picture; can you describe it?

P: Ehh well this is eh docu::: eh $\gg>>$ we have a family of $\wedge \wedge$ three. Mother ehh a girl $\wedge \wedge>>$ This one is trying to ehh shem:::: cheff $\wedge \wedge$ This is cheff $\wedge \wedge$ cooking ehh $\gg \gg>$ putting the cooking jar $\gg>$ inside the shelf and this one is ehh::: standing on the $\mathrm{st}^{\wedge} \wedge \mathrm{stu}^{\wedge} \wedge$ stool and this one is trying to have:: Ehh trying to $>>$ ehh reservly ehh reserve $\gg>\mathrm{re}^{\wedge} \wedge$ receive $\mathrm{A}^{\wedge} \wedge$ to receive plate $\wedge \wedge$ yah plate to younger brother $\wedge \wedge$ the mother washing plate here and gas, gas coo::: gas ehh cooker, gas cooker here. Dis is the window $\wedge \wedge$ cabinet $\wedge \wedge$

(Spouse attempts to help patient but the researcher forbids him)

$\mathrm{R}$ : Do you think any of the child is trying to fall down from the chair?

P: Ah yes, yes

$\mathrm{R}$ : And is water overflowing somewhere?

$P$ : Yes definitely

$\mathrm{R}$ : Is any window open or closed in the picture?

P: Close eh opened, is opened 
Key:

Required pause: $\wedge \wedge$

Unsolicited pause: >>>

Lengthening: :::

5) We have a family of three

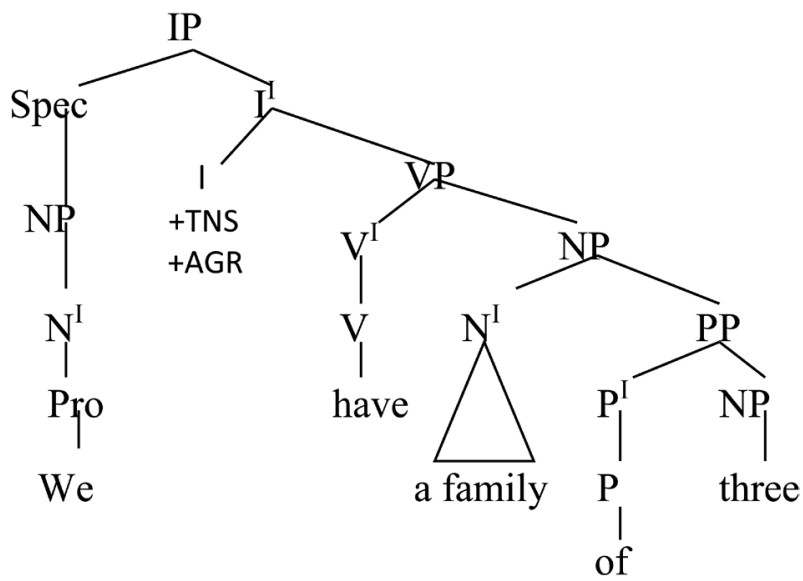

6) ${ }_{I P, S p e c, N P}$ This VPis ${ }_{N P}$ cheff.

7) ${ }_{I P, S p e c}$ NPThis ${ }_{V P}$ is ${ }_{N P}$ the window cabinet.

8) This one is trying to

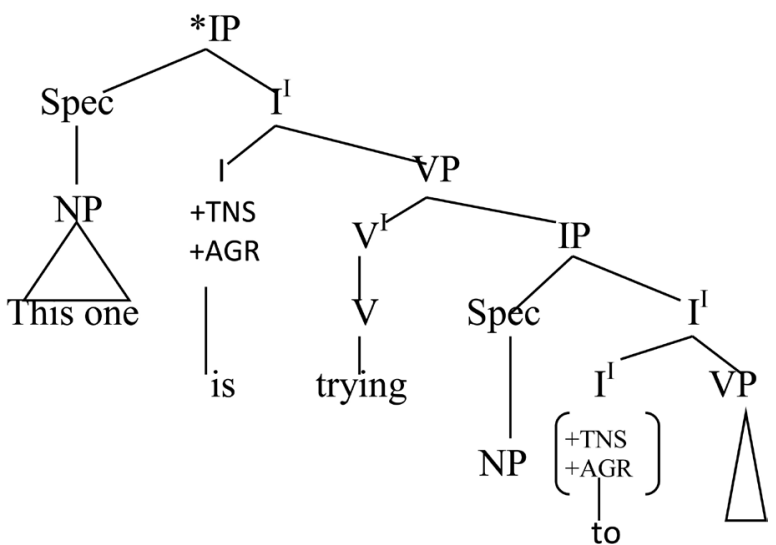

9) The mother washing plate here

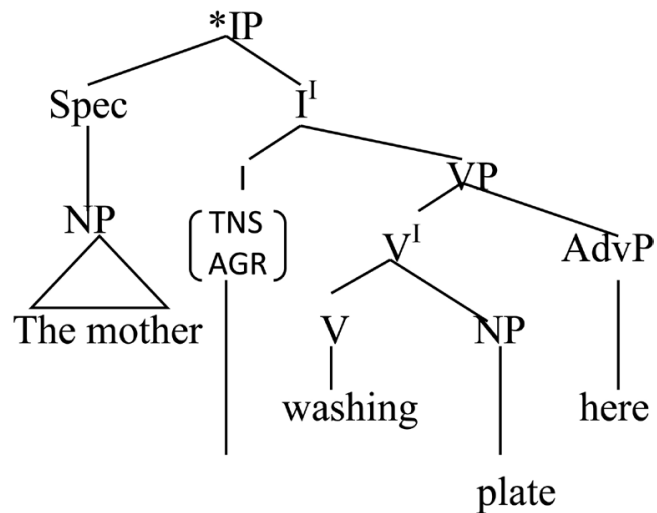


10) Gas cooker here

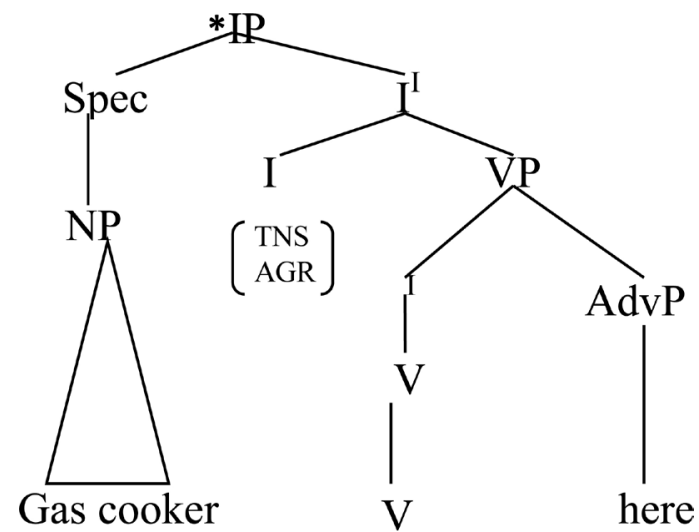

11) ...v ${ }_{\mathrm{V}}$ receive ${ }_{N P}$ plate ${ }_{P p}$ to younger brother

The structures above reveal that the SVO order of English sentence is preserved in the participant's speech. This is marked by the sequencing of Spec, IP-(Inf)-VP - in the structures. For example, sentence 5 has the Spec, IP-VP-NP (which gives SVO), sentences 6 and 7 have Spec, IP-VP-NP order, where the V is copular in both (thus giving SVC structure). The word order is preserved in the sentences without impairment to any of the elements in the order. Hence, the sentences are grammatical and comprehensible for listeners. However, structures 8 to 10 show some peculiarities. In 8 for instance, the matrix clause has Spec, IP-VP-IP order, showing SVO order where the VP complement (that is, the Object element of the sentence) is an embedded clause. While the word order appears to be preserved at the matrix clause level with the VP constituents preserved, the entire VP of the embedded clause is elided even though the infinitival to (to-inf), which is the functional head in the clause is phonetically projected. This elision points toward word retrieval problem in the participant's speech, and thus results in unacceptability of the sentence as it poses some comprehension challenge to the audience. While structures 9 is seen to have the SVOA (Spec, IP-VP-NP-AdvP), it could only be assumed that the intended structure in sentence 6 is SVA (Spec, IP-[VP]-AdvP). In 9, the VP requires an obligatory Infl. Marker for grammaticality; this is elided in the participant's production. Thus, the sentence is ungrammatical. Similarly, the omission of the $\mathrm{V}, \mathrm{VP}$ in sentence 10 results in the impairment of the sentence's word order. The verb is the most important element of a clause; it determines the role of nominal arguments in a sentence. Since this important element is elided, the role of the nominal "gas cooker" (in 10) cannot be determined. The deficit is 9 is somewhat different from what obtains in 8 to 10 . In this case, the participant produced the VP-NP-PP (which gives a VOA order). However, the A element is impaired as a result of displaced functional head. Instead of the required "from", the participant selected "to". The syntactic implication of this is that the thematic role of the action expressed by the verb is that of agent (the subject NP [this one] and benefactor (the internal argument [younger brother]). This thematic role re- 
quires the oblique head "from" as against the produced "to". This results in semantic loss.

\section{Discussion}

Generally, the data reveals that insertion of unsolicited lexical items, as well as repetition characterizes the participant's speeches in both languages. The analysis shows that the participant has problem with word retrieval in the L2 but not in the L1. This is manifest in his difficulty with making accurate lexical selection to express the content of the picture. Reference instances here are "trying to ehh shem:::: cheff" and "...trying to have::: ehh trying to ehh reservly ehh reserve $>$ re^^ receive ${ }^{\wedge}$ to receive plate ${ }^{\wedge}$ yah plate to younger brother". In both examples, it is obvious that the target words are "cheff" and "receive" respectively. It took the participant a longer time and attempt before he could access these words.

Also, syntactic deficits characterized with verb deletions are observed in the participant's English speech (L2) compared to the Yoruba speech (L1). The participant's English speech was characterized with omission of article, functional heads, lexical heads and verbs. Also, verb serialization was observed in the participant's English. An instance is seen in...cheff $\wedge$ cooking ehh $\gg>>$ putting the cooking jar > >inside the shelf... It is important to note that verb serialization is a syntactic feature characteristic of Yoruba but alien to English. This may be because both languages share the same semantic system but the lexical activation (sub) system is distinct, but partly specific, for both languages. As stated earlier, the linguistic domain approach holds that there is a single neural representation (semantic) for bilingual languages. This neural representation might be the anterior temporal lobe and its surrounding regions in the left hemisphere which subserve the semantic system for both languages considering the nature of the participant's aphasia [14] [15] [16]. This finding implies that damage is done at the lexical level and not the semantic level. This finding is consistent with some psycholinguistic models that are based on the assumption that words of each language of bilingual individuals are represented separated at the lexical level, and connected indirectly via common semantic system that is accessed independently from each lexicon [17] [18].

Furthermore, this study is consistent with the hierarchical model of bilingual lexical representation suggested by Kroll \& Stewart [19]. The sentence production deficits exhibited by AA suggest that bilingual individuals might possess two separate switching mechanisms: a lexical and a semantic mechanism. The findings of this case study provide evidence that English (the acquired language), as a second language, is represented in the brain by a lexical subsystem that does not represent Yoruba (the first language), and that this lexical subsystem is more fragile, and therefore more sensitive to brain damage. The finding of this case study is also consistent with Ibrahim [11] who reported that acquired language is more susceptible to brain damage than native language. 


\section{Conclusions}

Data from the present investigation of AA, a bilingual agrammatic aphasic patient, strongly support the existence of distinct language-specific lexical-subsystem centres in the Broca's complex for the native and acquired languages (YorubaEnglish). This study shows that acquired language is more susceptible to brain damage than native language. This might imply that deficit in speech production in both native and acquired language of bilingual aphasics may be influenced by the size of lesion in the Broca's complex or region.

A limitation of this study is that the participant in this study did not undergo an MRI assessment due to probable unavailability of this technology in some parts of Nigeria and this informed the authors to employ a neurolinguistic approach. Also, emphasis was only on spoken language with emphasis on deficits in spontaneous sentence production due to the purpose of the study. A self-designed aphasia screening test was used because of unavailability of a more reliable aphasia screening battery to the authors. Agrammatic aphasia screening was therefore based on the patient's medical records, referral report and outcome of a self-designed aphasia screening test. Nevertheless, this case report might shed light on the language organization especially in the Broca's complex or region, while also providing new evidence contributing to a better understanding of the dynamics of processing two languages in an agrammatic bilingual brain.

\section{Conflict of Interest}

The authors declare that they have no conflicting interest.

\section{References}

[1] Friedmann, N. (2006) Speech Production in Broca's Agrammatic Aphasia: Syntactic Tree Pruning. In: Amunts, K. and Grodzinsky, Y., Eds., Broca's Region, Oxford University Press, New York. https://doi.org/10.1093/acprof:oso/9780195177640.003.0005

[2] Ardila, A. (2010) A Proposed Reinterpretation and Reclassification of Aphasic Syndromes. Aphasiology, 24, 363-394. https://doi.org/10.1080/02687030802553704

[3] Ardila, A. (2015) Aphasia Handbook. Florida International University, Miami.

[4] Kemmerer, D. (2015) Cognitive Neuroscience of Language. Psychology Press. Taylor and Francis Group, New York and London.

[5] Speer, P. and Wilshere, C. (2014) What's in a Sentence? The Crucial Role of Lexical Content in Sentence Production in Nonfluent Aphasia. Cognitive Neuropsychology, 30, 507-543. https://doi.org/10.1080/02643294.2013.876398

[6] Moretti, R., Bava, A., Torre, P., Antonello, R.M., Zorzon, M., Zivandinov, R. and Cazzato, G. (2001) Bilingual Aphasia and Subcortical-Cortical Lesions. Perceptual and Motor Skills, 92, 803-814. https://doi.org/10.2466/pms.2001.92.3.803

[7] Paradis, M. (1990) Language Lateralization in Bilinguals: Enough Already! Brain and Language, 39, 576-586. https://doi.org/10.1016/0093-934X(90)90163-B

[8] Ojemann, G., Ojemann, J., Lettich, E. and Berger, M. (1989) Cortical Language Localization in Left, Dominant Hemisphere. An Electrical Stimulation Mapping Inves- 
tigation in 117 Patients. Journal of Neurosurgery, 71, 316-326.

https://doi.org/10.3171/jns.1989.71.3.0316

[9] Dehaene, S., Dupoux, E., Mehler, J., Cohen, L., Paulesu, E., Perani, D., van de Moortele, P.F., Lehéricy, S. and Le Bihan, D. (1997) Anatomical Variability in the Cortical Representation of First and Second Language. Neuroreport, 8, 3809-3815. https://doi.org/10.1097/00001756-199712010-00030

[10] Klein, D., Milner, B., Zatorre, R.J., Zhao, V. and Nikelski, J. (1999) Cerebral Organization of Bilinguals: A PET Study of Chinese-English Verb Generation. Neuroreport, 10, 2841-2846. https://doi.org/10.1097/00001756-199909090-00026

[11] Ibrahim, R. (2009) Selective Deficit of Second Language: A Case Study of a Brain-Damaged Arabic-Hebrew Bilingual Patient. Behavioral and Brain Functions, 5, 17. https://doi.org/10.1186/1744-9081-5-17

[12] Green, D.W. and Price, C.J. (2001) Functional Imaging in the Study of Recovery Patterns in Bilingual Aphasia. Bilingualism: Lang Cognition, 4, 191-201. https://doi.org/10.1017/S1366728901000281

[13] Goodglass, H. and Kaplan, E. (1972) The Assessment of Aphasia and Related Disorders. Lea \& Febiger, Philadelphia.

[14] Jefferies, E. and Lambon Ralph, M.A. (2006) Semantic Impairment in Stroke Aphasia versus Semantic Dementia: A Case-Series Comparison. Brain, 129, 2132-2147. https://doi.org/10.1093/brain/awl153

[15] Lambon-Ralph, M.A., Jefferies, E., Patterson, K. and Rogers, T.T. (2017) The Neural and Computational Basis of Semantic Cognition. Nature Reviews Neuroscience, 18, 42-55. https://doi.org/10.1038/nrn.2016.150

[16] Chen, L., Lambon-Ralph, M.A. and Rodgers, T.T. (2017) A Unified Model of Human Semantic Knowledge and Its Disorders. Nature Human Behaviour, 1, 0039. https://doi.org/10.1038/s41562-016-0039

[17] Schwanenflugel, P. and Rey, M. (1986) Interlingual Semantic Facilitation: Evidence for a Common Representational System in the Bilingual Lexicon. Journal of Memory and Language, 25, 605-618.

[18] Chen, H.C. and Leung, Y.S. (1989) Patterns of Lexical Processing in a Non-Native Language. Journal of Experimental Psychology: Learning, Memory, and Cognition, 15, 316-325. https://doi.org/10.1037/0278-7393.15.2.316

[19] Kroll, J.F. and Stewart, E. (1994) Category Interference in Translation and Picture Naming: Evidence for Asymmetric Connections between Bilingual Memory Representations. Journal of Memory and Language, 33, 149-174. https://doi.org/10.1006/jmla.1994.1008 
Submit or recommend next manuscript to SCIRP and we will provide best service for you:

Accepting pre-submission inquiries through Email, Facebook, LinkedIn, Twitter, etc. A wide selection of journals (inclusive of 9 subjects, more than 200 journals)

Providing 24-hour high-quality service

User-friendly online submission system

Fair and swift peer-review system

Efficient typesetting and proofreading procedure

Display of the result of downloads and visits, as well as the number of cited articles Maximum dissemination of your research work

Submit your manuscript at: http://papersubmission.scirp.org/

Or contact jbbs@scirp.org 